\title{
Marginalized Bodies of Imagined Futurescapes: Ableism and Heteronormativity in Science Fiction
}

\author{
By Josefine Wälivaara
}

\begin{abstract}
This article aims to contribute to an understanding of marginalized bodies in science fiction narratives by analyzing how physical disability and homosexuality/ bisexuality have been depicted in popular science fiction film and television. Specifically, it analyzes what types of futures are evoked through the exclusion or inclusion of disability and homo/bisexuality. To investigate these futurescapes, in for example Star Trek and The Handmaid's Tale, the paper uses film analysis guided by the theoretical approach of crip/queer temporality mainly in dialogue with disability/crip scholar Alison Kafer.

Although narratives about the future in popular fiction occasionally imagines futures in which disability and homo/bisexuality exist the vast majority do not. This article argues that exclusion of characters with disabilities and homo/bisexual characters in imagined futures of science fiction perpetuate heteronormative and ableist normativity. It is important that fictional narratives of imagined futures do not limit portrayals to heterosexual and able-bodied people but, instead, take into account the ableist and heteronormative imaginaries that these narratives, and in extension contemporary society, are embedded in.

Moreover, it is argued that in relation to notions of progression and social inclusion in imagined futurescapes portrayals of homo/bisexuality and disability has been used as narrative devices to emphasis "good" or "bad" futures. Furthermore, homo/bisexuality has increasingly been incorporated as a sign of social inclusion and progression while disability, partly due to the perseverance of a medical understanding of disability, instead is used as a sign of a failed future. However, the symbolic value ascribed to these bodies in stories are based on contemporary views and can thus change accordingly. To change the way the future is envisioned requires challenging how different types of bodies, desires, and notions of normativity are thought about. Sometimes imaginary futures can aid in rethinking and revaluating these taken-for-granted notions of normativity.
\end{abstract}

Keywords: future, science fiction, disability, queer, temporality

Wälivaara, Josefine "Marginalized Bodies of Imagined Futurescapes: Ableism and Heteronormativity in Science Fiction", Culture Unbound, Volume 10, issue 2, 2018 : 226-245. Published by Linköping University Electronic Press: http://www.cultureunbound.ep.liu.se 


\title{
Culture Unbound
}

\begin{abstract}
Nothing changes instantaneously.
In a gradually heating bathtub, you'd be boiled to death before you
\end{abstract}

knew it.

The Handmaid's Tale "Late" (2017)

Spock: One man cannot summon the future.

Kirk: But one man can change the present!

Star Trek: The Original Series “Mirror, Mirror” (1967)

The composition of imagined futurescapes in popular science fiction has been subjected to criticism due to the predominance of portrayals of homogenous societies and narratives inhabited mostly by white, male characters (see e.g. Nama 2008; Attebery 2002). Since the 1980s/1990s and onwards, more and more science fiction films and television series include women and people of color (Nama 2008: 38; Cornea 2007). Yet, homosexual/bisexual characters and characters with disabilities have been less frequently included in those futurescapes. In addition, not much scholarly attention has been payed to these narratives from the perspective of disability and/or queer studies. ${ }^{1}$

This article aims to contribute to an understanding of marginalized bodies in science fiction narratives by analyzing how physical disability and homosexuality/bisexuality have been depicted in popular science fiction film and television. Specifically, it analyzes what types of futures are evoked through the exclusion or inclusion of disability and homo/bisexuality. First, this article argues that the exclusion of characters with disabilities and homo/bisexual characters in imagined futures of science fiction perpetuate heteronormative and ableist normativity. Second, it is argued that in relation to notions of progression and social inclusion in imagined futurescapes portrayals of homo/bisexuality and disability has been used as narrative devices to emphasis "good" or "bad" futures. However, the symbolic value ascribed to these bodies in stories are based on contemporary views and can thus change accordingly.

Without entering into a debate on genre definitions (see e.g. Johnston 2011), this article assumes a broader approach to narratives invested in imagining futurescapes. The analysis will be limited to film and television series that relate specifically to the future by using an imagined future as setting. A lengthy analysis of specific films or television series will not be entered into, the article, instead, will take a broader approach by highlighting examples, including Star Trek (1966-) and The Handmaid's Tale (2017-), both of which directly portray utopian or dystopian futures.

To investigate these futurescapes, the article uses film analysis guided by the theoretical approach of crip and queer temporality, mainly in dialogue with disa- 
bility/crip scholar Alison Kafer who investigates "the imagined future invoked in popular culture, academic theory, and political movements" as a productive place for "[tracing] the ways in which compulsory able-bodiedness/able-mindedness and compulsory heterosexuality intertwine in the service of normativity" (Kafer 2013: 17). Building upon Kafer's argumentation on ideas of the future and its relationship to disability, which only in part deals with fiction, this article extends that theoretical notion into the field of science fiction studies and depictions of both disability and homo/bisexuality.

Homo/bisexuality and disability are brought together in this analysis as two examples of marginalized bodies which both have had a troublesome relationship with notions of futurity. As will be shown, they have been quite invisible in science fiction narratives. Moreover, both disability/crip and queer studies have theorized the notion of futurity through the lens of temporality (Kafer 2013; Samuels 2017; Edelman 2004; Halberstam 2005; Muñoz 2009; Freeman 2010). People with disabilities and LGBTQ people have been framed within a "no future" discourse in which they constantly are deferred from the notion of the future through a supposed consensus about the ideal future (Kafer 2013; Edelman 2004). Considering both disability and homo/bisexuality in light of this perceived troublesome relationship to the future can serve to highlight both similarities and differences between them. Moreover, using these two examples not only say something about matters of representations specific to these two groups but also facilitates a larger discussion on marginalized bodies in imagined futurescapes. ${ }^{2}$

While there are several differences in how characters with disabilities and homo/bisexual characters are portrayed, it is asserted here that much can be gained by considering them together. By relating depictions of disability and homo/ bisexuality in futurescapes this article brings to light differences as well as similarities between those representational practices. In particular, how similar discourses of these groups can have had similar effect on how they have been related to the future, but also how societal views and understandings of these groups has affected how they are depicted in narratives about the future. Moreover, putting two examples side by side can reveal more thoroughly how science fiction narratives involved in speculations about the future use marginalized bodies in the service of future discourses.

\section{Exclusion of Marginalized Bodies}

Among the large number of films and television series produced within the genre of science fiction examples where disability and homo/bisexuality is included only consist of a small fraction. While the vast majority of popular science fiction films and television series have excluded people with disabilities and homo/bisexual pe- 
ople altogether, there are, however, examples where characters with disabilities and homo/bisexual characters have been included. ${ }^{3}$ As of yet, I have not encountered any character who clearly belongs to both groups, i.e. a homo/bisexual character with a physical disability.

There are some difficulties of doing this overview in terms of definitions and differences between depictions of disability and homo/bisexuality. Not all homo/bisexual characters are explicitly portrayed as homo/bisexual but they have instead been interpreted as such by fans and/or scholars. In addition, disability in storytelling has often been used as a "narrative prosthesis" suggesting that disability is constantly present in storytelling as "a stock feature of characterization and, [...] as an opportunistic metaphorical device" (Mitchell \& Snyder 2000: 47). Disabilities are thus used as narrative devices in stories, not primarily to deal with experiences of disability but instead to use disability as a symbol of something else. In science fiction in particular many characters with disabilities have been subjected to technological alterations, effectively "curing" them. Both of these representational traditions obscure the existence of these characters in science fiction. Consequently, there is an ambiguity of existence, as they are simultaneously there and not there.

Depictions of people with physical disabilities have recurred in science fiction throughout the history of the genre (see e.g. Allan 2013: 2; Bérubé 2005: 568). In film and television, examples range from Star Trek: The Original Series (19661969), The Bionic Woman (1976-1978), Star Trek: The Next Generation (19871994), RoboCop (1987), Star Trek: Deep Space Nine (1993-1999), Gattaca (1997), Alien Resurrection (1997), and the Star Wars films, to more recent examples such as the X-Men film series (2000-), Dark Angel (2000-2002), Avatar (2009), RoboCop (2014), Daredevil (2015-), Mad Max: Fury Road (2015), Rogue One (2016), and Star Trek: Discovery (2017-). Of these examples, eight portray characters in wheelchairs, three portray blind or visually impaired characters, and some include several characters with various types of disabilities. The majority of these characters have suffered injuries in battle or through accidents that caused their disability, few of these characters were born with disabilities, and the majority of them are male. Often those characters who become disabled through injuries in battle pair their disability with an active and risk-taking masculinity, a trait, which, in part, is the cause of their disability.

Many of the narratives base their conceptualization of disability on a medical perspective in which disability is considered in relation to cures. The portrayals of futurescapes in which cures of disability are highlighted are closely connected to a medical paradigm of disability. The notion of a cure makes visible the persistent return to what has been called "the medical model" in which disability is understood as a medical issue connected to the individual rather than to societal 
circumstances (see e.g. Goodley 2011: 5-10). Science fiction and disability scholar Kathryn Allen argues, "[t]he medical characterization of the disabled body as requiring cure - in order to become 'normal' - has become part of our larger cultural construction of disability" (Allen 2013: 9). Consequently, much science fiction has focused on the possibilities of technological cures of disability (Allen 2013: 8-9; Cheu 2002: 199; Norden 1994: 292-295). Allen argues,

the idea of curing the body of its infirmities is a powerful trope repeated throughout the entire history of the SF genre. From utopian SF that sees an end to disability $[\ldots]$ to dystopian SF scenarios of failed cures $[\ldots]$ or cures that are only available to the wealthy few [...], SF is quite an experienced practitioner in reflecting the ideology of the 'perfect body'. (Allen 2013: 9)

Johnson Cheu contends, "[p]opular media is already pushing society toward a Utopian model of bodily perfection and cure" (Cheu 2002: 198). These narratives perpetuate taken-for-granted notions and supposed consensus about the "good" future in which disability inevitably is eradicated (Kafer 2013: 3). The medical framing of disability serves as an effective way for narratives to eradicate disabled bodies from imagined futures. Consequently, disabled bodies are cured and, thus, are no longer part of the future.

In most early examples of homo/bisexuality, the characters' sexuality was implicitly or subtextually implied rather than explicitly portrayed. Partly due to the fact that films from Hollywood were subjected to the scrutiny of the Production Code from the 1930s to the 1960s, which effectively forbade depictions of homosexuality (see e.g. Russo 1981; Doherty 1999: 363; Wälivaara 2016: 99). Television was also regulated by the intended viewership of family audiences, taste, and traditional values (Arthurs 2004; Wälivaara 2016: 51-53). However, gay and lesbian film scholars, queer film scholars, as well as fans, have been decoding implicit portrayals of LGBTQ characters in film and television in general. For science fiction film and television, however, this remains unexplored territory, at least in scholarly writings. George Méliès's L'Éclipse du soleil en pleine lune from 1907 has been considered in terms of homosexuality (Cornea 2007: 14), as has the now classic 1950s film The Invasion of the Body Snatchers (1956) (Pearson 2008: 21). Characters such as Kirk and Spock in Star Trek: The Original Series (1966-1969) and subsequent films have been decoded as queer by fans and scholars alike (see e.g. Greven 2009: 5-7; Gwenllian-Jones 2002: 81-82). Although these characters have been decoded as queer, the source texts do not directly acknowledge these relationships that remain implicitly portrayed.

Portrayals of homosexual or bisexual characters have appeared more and more 
in science fiction throughout the years. Mainstream science fiction narratives that explicitly portray homosexuality or bisexuality are a $21^{\text {st }}$ century phenomenon. Recent years have shown an increase in the number of characters portrayed explicitly as homosexual or bisexual in science fiction cinema and television (Wälivaara 2016). These are exemplified by films and television series such as Dark Angel (2000-2002); Firefly (2002-2003); Battlestar Galactica (2004-2009); V for Vendetta (2005); Doctor Who (2005-); Torchwood (2006-2011); Caprica (2009); Stargate Universe (2009-2011); Orphan Black (2013-2017); Cloud Atlas (2012); Star Trek Beyond (2016); Ghostbusters (2016); The Handmaid's Tale (2017-); and Star Trek: Discovery (2017-). A majority of these examples portray female characters who are bisexual or lesbians, however, few are main characters. Of these examples, only Torchwood portrays a protagonist that is homo/bisexual. ${ }^{4}$

There are changes over time and between portrayals of disability and of homo/bisexuality. While depictions of homo/bisexuality have undergone changes from implicit to explicit, the predominance of cure narratives for characters with disabilities does not seem to have changed to any significant extent. However, I would contend that in contemporary science fiction, they are both increasingly visible, and more often portrayed as complex characters where both disability and sexuality are considered intrinsic parts of being human in the future. But, those examples remain few in the light of the large amount of science fiction narratives produced for film and television.

\section{Imagining the Future}

Why then is it important that narrative fiction, even though set in far-removed worlds or, in this case, futures, include marginalized bodies? Although stories in popular culture clearly take place within their own fictional universes - some very similar to our own, and others less alike - they are all connected to the society and culture in which they were made. Realist genres often claim much affinity to the "real" world by using actual settings, human subjects, and a close proximity to the reality we are used to. However, these stories cannot claim to be anymore reality than fantastic fiction due to their constructed nature. While a discussion on the boundaries of reality is beyond the scope of this article, it will simply be asserted that fiction is always connected to current issues in society. All fiction is a product of a specific time, place, and culture that influence the way the stories are constructed and what discourses they are part of. Popular culture not only says something about the creators of fiction and their subjective world view, but its popularity also testifies to wider discourses in society today.

Not only is science fiction narratives always produced at a specific time and place but the genre has also often been discussed in terms of its commentary on present society (see e.g. Kuhn 1990: 15-8; Nama 2008: 5; Telotte 2001: 95-7; Johns- 
ton 2011: 28-30). Science fiction scholar Brian Attebery argues, "[b]y using images of the future to describe the present, the popular media invite us to use futuristic scenarios as tests of viability. Any group that cannot negotiate a place for itself in the imagined future is already obsolete" (Attebery 2002: 191). To exclude, for example, people with disabilities from these futures not only reflects an imagined future but, more importantly, the reality of the present. Allan argues, "While the settings and temporal framework of SF may differ dramatically from our own current reality, the way in which disability and people with disabilities are represented - as well as the technology that is used to contain or cure them - often directly reflects present-day biases and stereotypes" (Allen 2013:3). The images of the future presented in fiction are closely connected to the ideals and norms of the present.

The stories we are told about ourselves and others impact the way we understand our society and how we view and value people. Studies indicate that media representations impact the audience in terms of identity construction, norms, and attitudes (Gomillion and Giuliano 2011; Bonds-Raacke et. al. 2007; Kama 2004; Brown 2002). With reference to Paul Longmore, Katie Ellis writes "through repetition, on both film and television, characterisations of people with disability as criminals and sexual and social outcasts have a material effect on the position of people with disability in society" (Ellis 2015: 60). To constantly meet the same type of stories and stereotypes, not only in fiction but also in other parts of society, can influence one's world view. Certain groups, in particular those already marginalized in society, are constantly framed within the same type of story, which contributes to normative understandings of these groups. They are normative in the way they help sustain normative notions about groups, often by clear divisions between us/them and normal/deviant.

\section{Heteronormativity, Ableism, and Resistance}

The exclusion of people with disabilities and homo/bisexuality from futurescapes perpetuates heteronormativity and ableist normativity. Simply put, heteronormativity is the normative notion that everyone is heterosexual, and this is a normal and natural way of being (Rosenberg 2002). Ableism according to disability scholar Fiona Kumari Campbell is, "[a] network of beliefs, processes and practices that produces a particular kind of self and body [...] that is projected as the perfect, species-typical and therefore essential and fully human. Disability then is cast as a diminished state of being human" (qtd. in Campbell 2009: 5). Similar to racism and sexism, ableism is a discriminatory power structure that upholds able-bodiedness/able-mindedness as superior and disability as inferior.

Heteronormativity and ableist normativity are upheld by similar strategies. Campbell contends that ableism is produced through the notion of normality and the constitutional division between normal and aberrant (Campbell 2012: 215). 
Queer scholar Tiina Rosenberg describes how heteronormativity is perpetuated based on principles of exclusion: through the division between us and them - and inclusion: through assimilation, silence, or by ignoring deviance (Rosenberg 2002: 102). A way to perpetuate these normative systems is, thus, to simply ignore and make invisible these groups, for example, in fiction. While fiction is not the only site for visibility, it is part of a larger picture of society. As such, these fictional narratives that fail to acknowledge human diversity and display a society in which only the normative exists play a part in upholding ableism and/or heteronormativity.

Excluding certain groups from an imagining of the future also suggests the dominant view of the construction of identities of the present. This view suggests a type of ahistorical future that affects what is seen as a product of society, culture, and history - and what is considered something essential and everlasting. Science fiction scholar Veronica Hollinger argues:

Although sf has often been called 'the literature of change', for the most part it has been slow to recognize the historical contingency and cultural conventionality of many of our ideas about sexual identity and desire, about gendered behavior and about the 'natural' roles of women and men. [...] It assumes that the social roles played by women and men as women and men are ahistorical, that they will remain largely unchanged even in the distant future. (Hollinger 2003: 126)

While many science fiction narratives now have come to consider that gender roles might change in the future, few has of yet explored how notions of sexuality and ability will change, and the fact that these also are categories that are culturally and historically constructed. "Critics of sf have generally agreed that science fiction is a 'literature of ideas'. [...] Sexuality is also an idea. [...] For many people, however, sexuality - and particularly heterosexuality - can be envisioned only within the category of the 'natural'. To these people, sexuality is quite specifically not an idea" (Pearson 2003: 149). Partly, thanks to queer theory (hetero)sexuality has increasingly been understood as an idea which is historically, culturally and socially constructed. This same notion of disability has not, as of yet, however had the same impact on society.

From the perspective of crip theory, disability is understood in similar terms as queer theory understands sexuality. Robert McRuer (2006) argues: "Able-bodiedness, even more than heterosexuality, still largely masquerades as a nonidentity, as the natural order of things" (1). His theory explains how disability is produced through "the system of compulsory able-bodiedness" (McRuer 2006: 2). In studies of ableism, disability is conceptualized through relationships (Kafer 2013; 
Campbell 2012). Kafer (2013) argues, "not only does disability exist in relation to able-bodiedness/able-mindedness, such that disabled and abled form a constitutive binary, but also, [...], disability is experienced in and through relationships; it does not occur in isolation" (8). From these perspectives, disability is not seen as something essential and naturalized, but in fact as socially, historically, and culturally constructed. Suffice to say that current ideas of sexuality and disability have not been the same for the last 100 years (nor are they the same across the globe), and they will not be the same in a 100 years' time or in non-human societies.

When most popular imaginations of futurescapes exclude people with disabilities and homo/bisexual people, these imaginings embrace and perpetuate both ableist normativity and heteronormativity. In contrast, examples in which these marginalized bodies do appear can, instead, become sites of resistance. Scholars of cultural studies have long understood popular culture as "a site that both embraces and resists hegemonic culture" (Dhaenens 2013: 305). From this perspective, popular culture "can be empowering to subordinate and resistant to dominant understandings of the world" (Storey 2015: 92). This can more specifically come to mean, "articulations of queerness within popular television expose, unsettle, and/ or subvert the ubiquitous institutions and practices of heteronormativity" (Dhaenens 2013: 305). Popular culture, such as those science fiction narratives dealt with in this article, can thus play a part in not only perpetuating but also disrupting normativity.

However, that does not mean that all inclusion automatically is subversive. The issue is not to argue that all visibility and all portrayals that include marginalized bodies by default disrupt or subvert normativity. For example, the uses of stereotypes are instead a way to perpetuate normative systems such as ableism or heteronormativity. Cinema scholar Richard Dyer contends, "[ $t]$ he stereotype is taken to express a general agreement about a social group, as if that agreement arose before, and independently of, the stereotype" (Dyer 2002: 14). Stereotypes are, according to Dyer, part of creating normative assumptions about certain groups. While heterosexual and able-bodied characters are often portrayed as dynamic characters, homo/bisexual and characters with disabilities have long been reduced to one or two defining traits in cinema (see e.g. Norden 1994; Russo 1981). This is a way to create and sustain the division between us and them, between the normal and the deviant. How disability and homo/bisexuality are portrayed when included and what those portrayals come to mean thus remain relevant. For this study however, the question is not primarily of positive or negative portrayals, but first, the existence of marginalized groups in these futurescapes and second, what types of futures that are commonly evoked through the inclusion of homo/bisexuality and disability. 


\section{Inclusive Futures?}

The future, or perhaps more accurately, futures are commonly evoked in science fiction narratives. Whether it is the futuristic city of Metropolis (1927), the time-travels of Doctor Who (1963-1989; 2005-), the utopian future of the Star Trek franchise, or the dystopian future of The Handmaid's Tale (2017-), they all portray imagined futures. Imagined futures can, in the words of Kathryn Allen, testify to "the ability of SF to act as an early warning system: what are the possible futures, both positive and negative, that can arise out of our current potentialities?" (Allen 2013: 3). Studying stories about the future can convey the types of future imaginaries, i.e. "ideas about the future which, at least in some [...] quarters, become taken-for-granted or congealed discourses" (Goode \& Godhe 2017: 123) that are at stake. For the purpose of this article I discuss future imaginaries connected to disability and homo/bisexuality in relation to notions of progression and social inclusion in futurescapes exemplified by Star Trek, The Handmaid's Tale and Torchwood (2006-2011).

\section{Progression, Development, and Social Inclusion}

Science fiction often imagines the future as framed by ideas about progression and civilization. Social changes, such as equality of genders and multicultural societies, are often deployed in future visions as a way of emphasizing the progression or regression of a society. These changes are either used as a sign of a degraded future in which social inequalities are highlighted or used as a symbol of future unity and progression in a tolerant society. The former can be exemplified with The Handmaid's Tale, where the dystopian future is framed by the removal of women's right to their own bodies and a return to traditional values and patriarchal society. Issues such as prostitution and objectification of women have been used as signs of social corruption in order to emphasize "bad" futures not only in The Handmaids Tale, but also in Blade Runner (1982) and other examples.

Using these changes instead as a sign of social development is recurrently used in the Star Trek franchise which has deployed a "utopian social vision" (Jenkins 2004: 190) in which humanity has progressed beyond national borders, lives peacefully, and equality of gender and ethnicity is underlined as part of this development. For example, the idea of the future of humanity is, in the following scene from Star Trek: The Next Generation, upheld through progression in terms of gender equality. As first officer Riker (Jonathan Frakes) encounters the alien species Ferengi, who are appalled by the fact that humans allow their women to work, use firearms, and wear clothes, he defends their ignorance by contending: "I see them much as we were several hundred years ago [...] but we can hardly hate what we once were. They may grow and learn" ("The last outpost" 1987). In this example, the idea of the future is used as a marker of progression either compared to the 
past, or put in contrast to unevolved alien societies and species.

Partly due to this outspoken notion of social progression and utopianism in the future envisioned by Star Trek, fans have long criticized the exclusion of homosexual characters on the show (Jenkins 2004; Pearson 2008: 14-15). Not until the fall of 2017 was the first openly homosexual couple in a Star Trek series introduced in Star Trek: Discovery. ${ }^{5}$ Likewise, I would argue, there has been a similar absence of homo/bisexual characters in the majority of popular science fiction film and television until the beginning of the $21^{\text {st }}$ century. As stated earlier, there are exceptions where characters can be decoded as queer, but are not necessarily portrayed as homo/bisexual. For example through changing bodies from male to female and then encountering a past lover as in Star Trek: Deep Space Nine (1993-1999) episode "Rejoined" (1995). Where two people kiss whom at the time happens to have female bodies, but at the time of their actual relationship they were in fact in one male and one female body. If that should be interpreted as a same-sex relationship, a heterosexual relationship, or something else completely is the question.

I would contend that using homo/bisexuality in the framing of progressive or regressive future discourses was rare prior to the 2000s. After this time, homo/bisexual characters have been more explicitly included in science fiction film and television. Moreover, they have been used as a sign of cultural progression in terms similar to gender equality. One of the most pervasive examples of this is television series Torchwood (2006-2011), in which the idea of the future is framed by the notion of progression in terms of sexuality and gender. The protagonist Captain Jack Harkness (John Barrowman), born in the $51^{\text {st }}$ century, offers a future gaze at the present as he is trapped in the $21^{\text {st }}$ century. The future of humanity is portrayed through the omnisexual character Jack, who is a testament to the fact that contemporary views of sexuality and gender are in fact historical, social, and cultural constructions that will change over time. The progression of the future relies not only on technological advancements but also on sexual identities and categories. Jack contends that in the future of humankind, and in the encounter with alien species our current understanding of our sexualities are no longer viable.

The opposite can also be found where homophobic societies are used to signal dystopian futures. While The Handmaid's Tale (2017-) offers a clear critique of a dystopian society, it illustrates what has been called "reproductive futurism". In queer studies, Lee Edelman (2004) describes the prevalence of reproductive futurism in which the figure of the child symbolizes the future. He argues, "that queerness names the side of those not 'fighting for the children', the side outside the consensus by which all politics confirms the absolute value of reproductive futurism" (Edelman 2004: 3). Queerness, from this perspective, is the embodiment of the death drive (Edelman 2004: 27). The Handmaid's Tale portrays the threat 
posed to this future not only by feminism but also by queerness. Reproductive futurism is an example of a future imaginary, where reproduction and children are considered intrinsically bound to the future, and queerness symbolizes that which oppose this general consensus (Edelman 2004).

In the future society of Gilead the future is at stake due to infertility. This threat to the future of humankind is countered by the removal of rights for women, a return to traditional values, and executions of intellectuals and queers. The infertility is explained by authorities as caused by the extensive use of birth control pills, environmental damage, sexual liberation, and sinful behavior in the past. In The Handmaid's Tale, ways of life that oppose the heteronormative - preventing pregnancies, having sex outside of wedlock, with multiple partners, or with samesex partners - is presented as the cause of the future society's problems and, in extension, the end of humankind. The Handmaid's Tale portrays a dystopian future in which our contemporary achievements in terms of gender equality and equal rights for LGBTQ people are used against the inhabitants of Gilead. A return to traditional values, the nuclear family, and patriarchal society is considered to be the only way to ensure that the future is saved. The future imagined by the leaders of Gilead is a utopia for the chosen few, the rest are forced to make sacrifices to ensure the reproductive future of humankind. As the main character Offred (Elisabeth Moss) is told: "Better never means better for everyone... It always means worse, for some" ("Faithful” 2017).

Homo/bisexuality has in many ways started to be included in the future imaginary of development and progression. The framing of homo/bisexuality in these stories testify to discourses in society in which diversity and social inclusion is valued. Imagined futures can use these present-day discourses to conjure up good or bad futures, extrapolated based on those discourses. As this example, and the example with disability below will show, the symbolic value ascribed to marginalized bodies in stories are based on contemporary views and are therefore subjected to change over time. Moreover, the future imaginaries into which these stories position themselves in terms of progression and development is also based on normative notions of how to view the future.

Disability on the contrary has as of yet seldom been included in the notion of social equality as a way to emphasize progressive future societies. This notion of progression has an impact on the way disability has become related to the future. From the perspective of crip temporalities, Kafer writes, "disability is seen as the sign of no future, or at least of no good future" and adds that it is assumed, "that we all agree [...] that we all desire the same futures" (Kafer 2013: 3). Kafer argues that the disabled body has come to signify not having a future or that the future has failed. Due to the prevalence of the medical model of disability, a future in which disability is not eradicated is inevitably a failed future: 


\begin{abstract}
disability is cast as a problematic characteristic inherent in particular bodies and minds. Solving the problem of disability, then, means correcting, normalizing, or eliminating the pathological individual, rendering a medical approach to disability the only appropriate approach. The future of disability is understood more in terms of medical research, individual treatments, and familial assistance than increased social supports or widespread social change. (Kafer 2013: 5)
\end{abstract}

This prevalence of the medical paradigm in stories as well as in society offers insight into how the future of disability is viewed by contemporary society. Kafer's assertion about the future discourse of disability based on medical and individual definitions is highly viable in science fiction narratives. Consider for example the prevalence of cure narratives in science fiction (cf. Allen 2013). Science fiction (and science) continues to explore technological possibilities based on this medical model of disability:

With the recent cracking of genetic coding, opening up the possibility of genetic manipulation, a future where medical technology and genetic engineering will have advanced to the point where bodies can be genetically manipulated before birth, or treated and cured so as to make 'disability' obsolete, it is not beyond the realm of possibility. In this 'medical model', disability becomes non-existent. (Cheu 2002: 198)

The future is extrapolated based on ableist assumptions about the connection between health, progression, and disability. Moreover, the ideal future from that perspective is undoubtedly a future where disability has been eradicated. For fiction narratives dealing with the future, this medical progression or regression has come to symbolize utopian/dystopian futures. As Fiona Kumari Campbell argues, "[f]or disability, utopianism is a conflicted zone - there is no future existence, disability dreaming is expunged and the utopian drive is a device for promise (of curability), hence, extinction of the impairment state" (Campbell 2012: 223). Kafer also argues:

If disability is conceptualized as a terrible unending tragedy, then any future that includes disability can only be a future to avoid. A better future, in other words, is one that excludes disability and disabled bodies; indeed, it is the very absence of disability that signals this better future. The presence of disability, then, signals something else: a future that bears too many traces of the ills of the present to be desirable. (Kafer 2013: 2) 
As a narrative mechanism, the inclusion of disability in imagined futures often aims to emphasize "bad" futures. For example, one of the most obvious inferences to disability in The Handmaid's Tale is used to narratively underline decadence and corruption. In the scene in which Offered is taken to Jezebel's, a brothel to which influential men travel for sex with women forced into prostitution, the setting is introduced to us through Offered's gaze. She sees naked women, women dressed-up in various costumes and lingerie, men together with several women at the same time, people drinking and smoking, a sight in stark contrast to Offered's present existence as a handmaid. Moreover, she sees a man and a woman in an elevator, as the man passionately sucks on the woman's amputated arm. In this instance, disability is positioned to further symbolize the decadent space of Jezebel's.

There are, however, examples in which the medical model of disability is in negotiation with ideas of progression in terms of social equality. Star Trek's utopian vision of the future has been criticized for not including people with disabilities in any significant way (Kanar 2000). However, Star Trek: Discovery, has not only included a same-sex couple, but also characters with disabilities. While at the time of writing this only one season of Star Trek: Discovery is available, there are some indications that the creators want to problematize some previously taken-for-granted notions of the future of disability. So finally, one can say, disability is beginning to be included in the notion of the progressive future of Star Trek in which a variety of bodies, genders, and ethnicities are welcome. First of all, a crewmember of the Discovery is in passing shown in a wheelchair ("Magic to Make the Sanest Man Go Mad" 2017). The character is used to praise the sacrifices made by crewmembers in the ongoing war, i.e. the injuries acquired in battle are visualized by a crewmember in a wheelchair and partly adhere to a taken-for-granted ableist notion of loss and sacrifice. But, to see a character in Starfleet uniform who is not able-bodied is still an important step towards including a variety of bodies not as a sign of a failed future, but of a future of inclusiveness and equality. However, the character only appears briefly on screen.

In addition, the Captain of the U.S.S Discovery, Captain Lorca (Jason Isaacs), is introduced as having suffered an eye injury in battle, and, though he has the medical and technological possibility to simply "have it fixed," he has refused to do so. This refusal to make surgical corrections to his eyes can first be interpreted as an unwillingness to be "cured" and thus, choosing to live with a visual impairment. However, it is revealed later on in season one that Lorca in fact originates from a mirror universe, a parallel universe in which every human has this condition, a sensitivity to light. Is Lorca then to be considered a character with a disability only due to disabling circumstances in the prime universe, or is the visual impairments of the entire evil Terran Empire of the mirror universe to be read as a metaphor for their inability to see and value non-human species? This only 
difference between the prime universe (aka. the good guys) and mirror universe (aka. the bad guys) can thus instead be understood as utilizing bodily differences and disabilities as signs of character flaws rather than as portrayals of experiences of disability (cf. Bérubé 2005).

\section{Changes}

In the light of the discussion about disability and futurity I argue that the lack of homo/bisexual characters in early science fiction narratives also can be ascribed to the pathologization of homosexuality in a time in which medical discourses surrounding non-heterosexual sexualities dominated. It would then make sense that many stories would have done away with both disability and homosexuality in their imagined futurescapes based on the notion of an evolved progressive society.

Moreover, the changes in how homosexuality has come to be understood and defined over the course of 50 years have definitely affected the types of stories that have been told, what types of futures have been imagined, and what value and meaning have been ascribed to the presence of homo/bisexuality in imaginary futures. Likewise for disability, changes in how disability is understood and defined will affect portrayals and ascribed meanings in future settings. The shift from a purely medical understanding of disability to social, relational, and political frameworks has taken place later in time for disability than for homosexuality, and these efforts have not yet come to bear much fruit in fiction.

I have also argued that the kind of futures we imagine is bound to the way we understand the present. In this context, imaginations of the future are also political. For example, questioning the political aspects of disability according to Kafer, "requires a recognition of the central role that ideas about disability and ability play in contemporary culture, particularly in imagined and projected futures" (Kafer 2013: 10). The same goes for sexuality. Allen, likewise, identifies ways contemporary society thinks about disability as the area to be scrutinized.

When we imagine a future world without disability, we end up erasing a significant group of people from our ideal vision of a collective human identity and history. It is important that we interrogate these outdated cultural frames of disability and seek new ways of reading and writing the disabled body so that we, as a human community, might move forward into the future together. (Allen 2013: 14 my emphasis)

One place for finding new ways of thinking is through the stories told, for example, in popular culture about the imagined futures of humanity.

It is likewise important that scholars researching science fiction or futurescapes critically scrutinize the way these marginalized bodies are being portrayed. 
For example, by considering how different definitions and normative understandings effect not only the composition of stories but the framing of analysis. To change perspective produces other types of analysis not taking for granted preconceived meanings. For example, some stories that have mainly been discussed in terms of curing narratives of disability could also be understood as depicting a future society in which societal barriers have been removed. For example, characters such as Alex Murphy in the RoboCop films and Darth Vader in the Star Wars films are characterized by what Martin F. Norden (1994) calls "techno-marvels", characters that through technology been "cured" of her/his disability (Norden 1994: 292-295). ${ }^{6}$ Likewise, although not as extensive a technological alteration, Georgi La Forge (LeVar Burton) of Star Trek: The Next Generation applies technology to be able to see. If instead seen from the perspective of what disability scholars have called "the social model" (see e.g. Goodley 2011: 11-13), these futurescapes have, in many ways, solved certain societal barriers that create and sustain disability. This perspective emphasizes that we are not dealing with disabled people but with disabling environments. Instead of understanding technological hybridity as a way to cure these characters, it is possible to consider a technologically advanced society as a society better equipped for different kinds of bodies. From this perspective these three characters can, in contrast, be understood as existing in futurescapes in which physical injuries do not necessitate disability. If put into a non-futuristic environment, these characters would have been unmistakably disabled. Each of these futurescapes, however, offers fewer disabling circumstances. Technological advancements, such as Geordi's visor, are part of a society, which in comparison to the present, has become less disabling, at least for some (Kanar 2000).

\section{Conclusion}

Although narratives about the future in popular science fiction occasionally have imagined futures in which disability and homo/bisexuality exist and marginalized bodies are presented as an integral part of the imagined future, the vast majority do not. As this article has illustrated, the exclusion of characters with disabilities and homo/bisexual characters in imagined futures of science fiction perpetuate heteronormative and ableist normativity. It is important that fictional narratives of imagined futures do not limit portrayals to heterosexual and able-bodied people but, instead, take into account the ableist and heteronormative imaginaries that these narratives, and in extension contemporary society, are embedded in. A debate about the future of human society and what it means to be human, now and in the future, is currently underway in all parts of society. Therefore, it is important that people with disabilities and homo/bisexual people, or any marginalized 
group, exists in imagined futures not only on the terms of an ableist and heterosexist society.

Moreover, in examples where homo/bisexuality and disability have been included in imagined futures they are often deployed as narrative devices used to emphasis "good" or "bad" futures. In particular if connected to notions of progression and social inclusion. It is argued that homo/bisexuality has increasingly been incorporated as a sign of social inclusion and progression while disability, partly due to the perseverance of a medical understanding of disability, is more often used as a sign of a failed future. It has of yet seldom been used as a sign of a future society in which different types of bodies are embraced. However, as the example with homo/bisexuality show, the symbolic value ascribed to these bodies in stories are based on contemporary views and can thus change accordingly. To actually conjure up futures in which normative systems of ableism and heteronormativity are overthrown calls attention to the constructed nature of disability and sexuality. To change the way in which the future is envisioned in terms of the existence of marginalized bodies requires challenging how different types of bodies, desires, and notions of normativity are thought about. Sometimes imaginary futures can aid in rethinking and revaluating these taken-for-granted notions of normativity.

Josefine Wälivaara is a postdoctoral researcher in the ERC-funded research project DISLIFE Liveable disabilities: Life courses and opportunity structures across time, at Umeå University. She defended her dissertation in drama-theatre-film in 2016. Her research interests are popular culture, mainly cinema and television, with focus on normativity, disability, sexuality, gender, and storytelling. E-mail: josefine.walivaara@umu.se

\section{Acknowledgements}

This study is part of a project headed by Lotta Vikström that has received funding from the European Research Council (ERC) under the European Union's Horizon 2020 research and innovation programme (Grant Agreement No. 647125): 'DISLIFE Liveable Disabilities: Life Courses and Opportunity Structures Across Time'.

\section{Notes}

${ }^{1}$ For research into disability and science fiction see e.g. Allen 2013; Ellis 2015; Kanar 2000; Cheu 2002; Bérubé 2005; Cheyne 2012; Weinstock 1996; Moody 1997;. For queer studies of science fiction see e.g. Pearson et al. 2008; Ginn \& Cornelius 2012; Call 2013; Greven 2009; Ireland 2010; Wälivaara 2016.

${ }^{2}$ Throughout this paper I sometimes use "these groups" for lack of better words. However, I am aware that neither disability nor homosexuality/bisexuality unpro- 


\section{Culture Unbound}

Journal of Current Cultural Research

blematically can be grouped together as these represent homogenous identities, subgroups, etc.

${ }^{3}$ For the purpose of this discussion I use a broad definition of science fiction, not strictly limiting it to those clearly portraying futures (for example including Star Wars set "a long time ago"). This offers a more representative picture of portrayals of disability and homo/bisexuality in mainstream audio-visual science fiction.

${ }^{4} \mathrm{Or}$ in fact "omnisexual", see e.g. Ireland 2010: 1.

${ }^{5}$ In 2016, the film Star Trek Beyond revealed that, in the alternative timeline, Sulu had a husband.

${ }^{6}$ For a more elaborated discussion on Darth Vader and disability, see: Norden 1994: 292-295; Covino 2013; and Wälivaara 2018.

\section{References}

Allen, Kathryn (ed.) (2013): Disability and Science Fiction. Representation of Technology as Cure, New York: Palgrave Macmillan.

Arthurs, Jane (2004): Television and Sexuality: Regulation and the Politics of Taste, Maidenhead: Open University Press.

Attebery, Brian (2002): Decoding Gender in Science Fiction, New York: Routledge.

Bérubé, Michael (2005): "Disability and Narrative", PMLA, 120:2, 568-76.

Bonds-Raacke, Jennifer M., Elizabeth T. Cady, Rebecca Schlegel, Richard J. Harris, and Lindsey Firebaugh (2007): "Remembering Gay/Lesbian Media Characters", Journal of Homosexuality, 53:3, 19-34.

Brown, Jane D. (2002): "Mass media influences on sexuality", The Journal of Sex Research, 39:1, 42-45.

Call, Lewis (2013): BDSM in American Science Fiction and Fantasy, New York: Palgrave Macmillan.

Campbell, Fiona Kumari (2009): Contours of ableism: the production of disability and abledness, New York: Palgrave Macmillan.

Campbell, Fiona Kumari (2012): "Stalking Ableism: Using Disability to Expose 'Abled' Narcissism”, Dan Goodley, Bill Hughes, \& Lennard J. Davis (eds.): Disability and Social Theory: New Developments and Directions, Basingstoke: Palgrave Macmillan, 212-230.

Cheu, Johnson (2002): "De-gene-erates, Replicants and Other Aliens: (Re)defining Disability in Futuristic Film", Mairian Corker and Tom Shakespeare (eds.): Disability/Postmodernity: Embodying Disability Theory, London: Continuum, 198-212.

Cheyne, Ria (2012): "Introduction: Popular Genres and Disability Representation", Journal of Literary \& Cultural Disability Studies, 6:2, 117-123.

Cornea, Christine (2007): Science Fiction Cinema: Between Fantasy and Reality, New Brunswick, N.J.: Rutgers University Press.

Covino, Ralph (2013): "Star Wars, Limb Loss, and What It Means to Be Human", Allen, Kathryn (ed.): Disability and Science Fiction. Representation of Technology as Cure, New York: Palgrave Macmillan, 103-113.

Dhaenens, Frederik (2013): "Teenage queerness: negotiating heteronormativity in the representation of gay teenagers in Glee", Journal of Youth Studies, 16:3, 304-317.

Doherty, Thomas (1999): Pre-Code Hollywood. Sex Immorality, and Insurrection in American Cinema 1930-1934, New York: Columbia University Press.

Dyer, Richard (2002): The Matter of Images: Essays on Representation, 2. ed. London: Routledge.

Edelman, Lee (2004): No Future: Queer Theory and The Death Drive, Durham: Duke 


\section{Culture Unbound}

University Press.

Ellis, Katie (2015): Disability and Popular Culture: Focusing Passion, Creating Community and Expressing Defiance, Burlington: Ashgate Publishing.

Freeman, Elizabeth (2010): Time binds: queer temporalities, queer histories, Durham: Duke University Press.

Ginn, Sherry and Michael G. Cornelius (eds.) (2012): The Sex Is Out of This World: Essays on the Carnal Side of Science Fiction, Jefferson, N.C. McFarland \& Company. Inc. Publishers.

Gomillion, Sarah C. and Traci A. Giuliano (2011): "The Influence of Media Role Models on Gay, Lesbian, and Bisexual Identity", Journal of Homosexuality, 58:3, $330-354$.

Goode Luke \& Michael Godhe (2017): "Beyond Capitalist Realism - Why We Need Critical Future Studies", Culture Unbound: Journal of Current Cultural Research, 9:1, 109-129.

Goodley, Dan (2011): Disability Studies: An Interdisciplinary Introduction. Los Angeles: SAGE.

Greven, David (2009): Gender and Sexuality in Star Trek: Allegories of Desire in the Television Series and Films, Jefferson, N.C.: McFarland \& Co.

Gwenllian-Jones, Sara (2002): "The Sex Lives of Cult Television Character", Screen 43:1, 79-90.

Halberstam, Judith (2005): In a Queer Time and Place: Transgender Bodies, Subcultural Lives, New York: New York University Press.

Hollinger, Veronica (2003): "Feminist theory and science fiction", Edward James and Farah Mendelsohn (eds.): The Cambridge Companion to Science Fiction, Cambridge: Cambridge University Press, 125-136.

Ireland, Andrew (ed.) (2010): Illuminating Torchwood: Essays on Narrative, Character and Sexuality in the BBC Series, Jefferson, N.C.: McFarland \& Co.

Jenkins, Henry (2004): "Out of the Closet and into the Universe": Queers and Star Trek", Benshoff, Harry M. \& Griffin, Sean (red.); Queer Cinema: The Film Reader. New York: Routledge, 189-207.

Johnston, Keith M. (2011): Science Fiction Film: A Critical Introduction, Oxford: Berg.

Kafer, Alison (2013): Feminist, queer, crip, Bloomington: Indiana University Press.

Kama, Amit (2004): "Supercrips versus the pitiful handicapped: Reception of disabling images by disabled audience members" Communications 29:4, 447-466.

Kanar, Hanley E. (2000): "No Ramps in Space: The Inability to Imagine Accessibility in Star Trek: Deep Space Nine", Elyce Rae Helford (ed.): Fantasy Girls: Gender in the New Universe of Science Fiction and Fantasy, Lanham, Md.: Rowman \& Littlefield, 245-264.

Kuhn, Annette (ed.) (1990): Alien Zone: Cultural Theory and Contemporary Science Fiction Cinema, London: Verso

McRuer, Robert (2006): Crip theory: cultural signs of queerness and disability. New York: New York University Press.

Mitchell, David T. \& Snyder, Sharon L. (2000): Narrative prosthesis: disability and the dependencies of discourse. Ann Arbor: University of Michigan Press.

Moody, Nickianne (1997): "Untapped Potential: The Representation of Disability/ Special Ability in the Cyberpunk Workforce", Convergence: The International Journal of Research into New Media Technologies, 3:3, 90-105.

Muñoz, José Esteban (2009): Cruising Utopia: The Then and There of Queer Futurity, NYU Press, New York.

Nama, Adilifu (2008): Black Space: Imagining Race in Science Fiction Film, 1. ed. Austin: University of Texas Press.

Norden, Martin F. (1994): The Cinema of Isolation: A History of Physical Disability in the Movies, New Brunswick, N.J.: Rutgers Univ. Press. 


\section{Culture Unbound}

Journal of Current Cultural Research

Pearson, Wendy G. (2003): "Science fiction and queer theory", Edward James and Farah Mendelsohn (eds.): The Cambridge Companion to Science Fiction, Cambridge University Press, 149-160.

Pearson, Wendy G. (2008): “Alien Cryptographies: The View from Queer”, Pearson, Wendy G., Hollinger, Veronica \& Gordon, Joan (eds.): Queer Universes: Sexualities in Science Fiction, Liverpool: Liverpool University Press, 14-38.

Pearson, Wendy G., Hollinger, Veronica \& Gordon, Joan (eds.) (2008): Queer universes: sexualities in science fiction, Liverpool: Liverpool University Press.

Rosenberg, Tiina (2002): Queerfeministisk Agenda, Stockholm: Atlas.

Russo, Vito (1981): The Celluloid Closet: Homosexuality in the Movies, 1st ed. New York: Harper \& Row.

Samuels, Ellen (2017): "Six ways of looking at crip time". Disability Studies Quarterly, 37:3, n.pag.

Star Trek: Deep Space Nine, s. 4, ep. 5, "Rejoined," Paramount Television, October 30, 1995.

Star Trek: Discovery, s. 1, ep. 7, "Magic to Make the Sanest Man Go Mad," CBS Television Studios et al., Netflix, October 292017.

Star Trek: The Next Generation, s.1, ep. 5, "The Last Outpost," Paramount Television, Netflix, October 171987.

Star Trek: The Original Series, s. 2, ep. 4, "Mirror, Mirror," Norway Productions et al., Netflix, October 61967.

Storey, John (2015): Cultural Theory and Popular Culture: An Introduction, Seventh edition. London: Routledge/Taylor \& Francis Group.

Telotte, J. P. (2001): Science Fiction Film, Cambridge: Cambridge Univ. Press.

The Handmaid's Tale, s. 1, ep. 3, "Late," MGM Television, HBO Nordic, April 26 2017.

The Handmaid's Tale, s. 1, ep. 5, "Faithful," MGM Television, HBO Nordic, May 10 2017.

Weinstock, Jeffery A. (1996): “Freaks in Space: 'Extraterrestrialism' and 'Deep-Space Multiculturalism",, Rosemarie Garland Thomson (ed.): Freakery: Cultural Spectacles of the Extraordinary Body, New York: New York Univ. Press.

Wälivaara, Josefine (2016): Dreams of a subversive future: sexuality, (hetero)normativity, and queer potential in science fiction film and television. Diss. Umeå : Umeå University.

Wälivaara, Josefine (2018): "Blind Warriors, Supercrips, and Techno-Marvels: Challenging Depictions of Disability in Star Wars", The Journal of Popular Culture, 51:4, 1036-1056. 